SHS Web of Conferences 2, 00018 (2012)

DOI: $10.1051 /$ shsconf $/ 20120200018$

(C) Owned by the authors, published by EDP Sciences, 2012

\title{
Importance of exercise and motor fitness in 11-13 year old primary school children in liechtenstein
}

\author{
J. Kühnis
}

University of Teacher Education Central Switzerland

\begin{abstract}
Several studies have shown that the behavioral pattern in exercise and motor fitness of children has changed dramatically in the last two generations. Because childhood is a very important period of life, the promotion of physical activity (PA) has been identified as a major public health priority. Therefore the aim of this study was to observe the fitness level and the importance of PA among $5^{\text {th }}$ grade pupils in Liechtenstein. This cross-sectional study was carried out from March to June 2007. A total of 313 children (aged $11.8 \pm 0.6$ years) were randomly selected. PA and socio-demographic data were acquired with a short questionnaire, the motor fitness with a test battery, consisting of eight items. In summary, the physical performance of all the children is satisfactory, but with obvious deficits in coordination, flexibility and basic motor skills. Children's general fitness was significantly higher among those, who were members of sports clubs than non members $(\mathrm{p}<.05)$. A high level of PA in free time was associated with better motor fitness $(\mathrm{p}<.001)$. According to other studies, this survey illustrates the controversial findings of a high participation in sports of school children in their free time activities but at the same time increasing motor disorders.
\end{abstract}

Key words: motor fitness, primary school children

Physical activity (PA) is a crucial source of children's health. Various age-appropriate motor experiences support growth, promote motor abilities and improve psychosocial health (Hallal et al., 2006; Strong et al., 2005; Zimmer, 2009). Therefore the school age is a very important period of life, in which motor skills and healthy long-term lifestyle patterns can be established (Ahnert and Schneider, 2007; Janz, 2000; Tammelin, 2005). According to current state of research, this health potential seems to be used however less and less.

In our consumer-oriented and media-impacted society, lifestyles and habits appear to have changed decisively. Children and adolescents of today frequently show an inactive lifestyle, unhealthy nutritional habits as well as media-dominated recreational activities (Graf et al., 2006; Must and Tybor, 2005; Hills et al., 2007). At the same time an increasing polarisation can be detected amongst adolescents whose daily routine is either physically active or inactive, or whose diet is healthy or unhealthy. As a result of this insufficient dose of daily exercise, not only postural disbalances among school children have increased but also the worldwide prevalence of overweight (Wang and Lobstein, 2006; Hills et al., 2007). Within Europe, the highest levels of childhood overweight (30-36\%) can be found in Mediterranean countries (Jackson-Leach and Lobstein, 2006). In Liechtenstein, the current prevalence of overweight among school children (incl. obesity) is $17.1 \%$, following the international IOTF-criteria (Kühnis and Walser, 2010).

According to the international HBSC-study (Health Behaviour in School-Aged Children) more than half of the 11-15 year olds fail to meet the recommended guidelines of at least an hour of moderate to vigorous PA per day (Currie et al., 2008). Many children exhibit poorer motor skills (Bös, 2003; Olds et al., 2006). In an apparent contradiction to this, club and informal leisure sports among

This is an Open Access article distributed under the terms of the Creative Commons Attribution License 2.0, which permits unrestricted use, distribution, and reproduction in any medium, provided the original work is properly cited. 


\section{SHS Web of Conferences}

children and adolescents continue to be rated highly today (Brettschneider et al., 2006). ${ }^{1}$ However, this sporting activity does not appear to compensate, or only partly, for the lack of exercise in daily routine (Brettschneider et al., 2006). With this background, this study offers representative data on the motor fitness and significance of exercise in $5^{\text {th }}$ grade pupils in Liechtenstein for the first time.

\section{Methods}

In this cross-sectional study, a national sample of 313 children (aged $11.8 \pm 0.6$ years) was randomly selected. The motor abilities were operationalised with the Munich Fitness Test (MFT), a standardised test procedure, which offers sex- and age-specific norm values. The test battery includes six items, covering the following central aspects of motor fitness: coordination (ball bouncing, goal throwing), strength (jump\&reach, bent-arm hang), flexibility (stand\&reach) and endurance (step test). This test profile was supplemented with two other items (somersault, rope skipping). General information about the participants (socio-demographic items, questions about their sportiness and importance of PA) were acquired with a short questionnaire. Statistical analyses were performed using SPSS (version 15). Group differences were assessed with Chi-square, T-test and ANOVA, drawn at significant level of 5\%.

\section{Results}

$74.1 \%$ of the observed children are members of sports club and $60.7 \%$ classified themselves as recreational athletes. $23 \%$ practise competitive sport and each $6^{\text {th }}$ pupil is hardly active or inactive. The proportion of membership in sports club was significant higher among boys $(\mathrm{p}<.05)$, among native or children from German-speaking countries $(\mathrm{CH}, \mathrm{A}, \mathrm{D})$ than children with a migrant background $(\mathrm{p}<.01)$ as well as from children whose parents were members of sports club than from families without membership $(\mathrm{p}<.001)$. Two-thirds evaluated sport activities as an "important or very important" aspect of their personal life. For 31.3\%, sport is just as important as other free time activities and for only $3.5 \%$ sport is unimportant. As expected, for the majority (51.4\%) physical education is their favourite subject at school, whereby the emphasis was significantly higher among boys $(\mathrm{p}<.001)$.

In summary (Figure 1), the primary students demonstrated a satisfactory test result (median $=46.8$ ), but obvious deficits in coordination, flexibility and basic motor skills and in total poorer proficiency than the German reference. Each $5^{\text {th }}$ respectively $4^{\text {th }}$ pupil showed insufficient motor abilities in the test items ball bouncing and goal throwing. Flexibility and extensibility of the retral musculature were also below average: $47.6 \%$ could not reach the sole of their foot with stretched arms and legs. Furthermore, questionable finding is that $43.1 \%$ were unable to do a proper somersault and $29.1 \%$ could not skip with a rope.

Children's general fitness was significantly higher among those who were members of sports clubs than non members $(\mathrm{p}<.05)$. A high level of PA in free time (Figure 2) was associated with better motor fitness $(\mathrm{p}<.001)$. Competitive sport oriented children reached best results over all test items, with the exeption of the step test. Their better fitness was also evident in the analysis of the supplemented test items somersault and rope skipping $(\mathrm{p}<.01)$. While the majority $(65.3 \%)$ of the competitive athletes fulfilled both exercises, the proportion among the recreational athletes is $41.6 \%$ and only $35.3 \%$ in the group of hardly active or inactive children.

\section{Discussion}

The findings highlight the following important issues. According to other studies (Klaes et al., 2008; Steffen et al., 2007), this survey emphasise the correlation between sportiness, membership in sports

\footnotetext{
${ }^{1}$ In Liechtenstein over $60 \%$ of the 11- and 20-year olds are members of sports club. Furthermore, sport was rated as the second most important leisure time activity (after meeting up with friends) (Kühnis, 2007).
} 
Int. Conf. SOCIETY. HEALTH. WELFARE; Congr. of Rehabilitation Doctors of Latvia

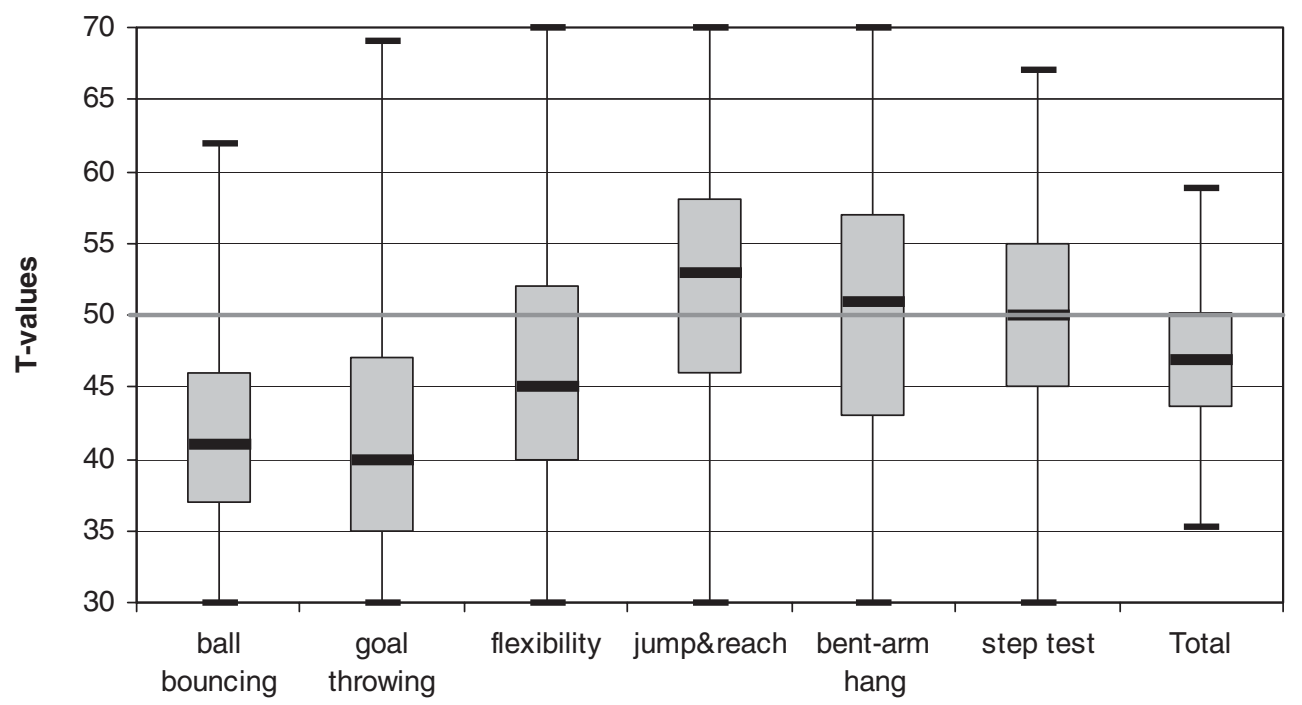

Figure 1. Boxplot of motor fitness $(\mathrm{N}=313)$ in comparison with German average (grey line).

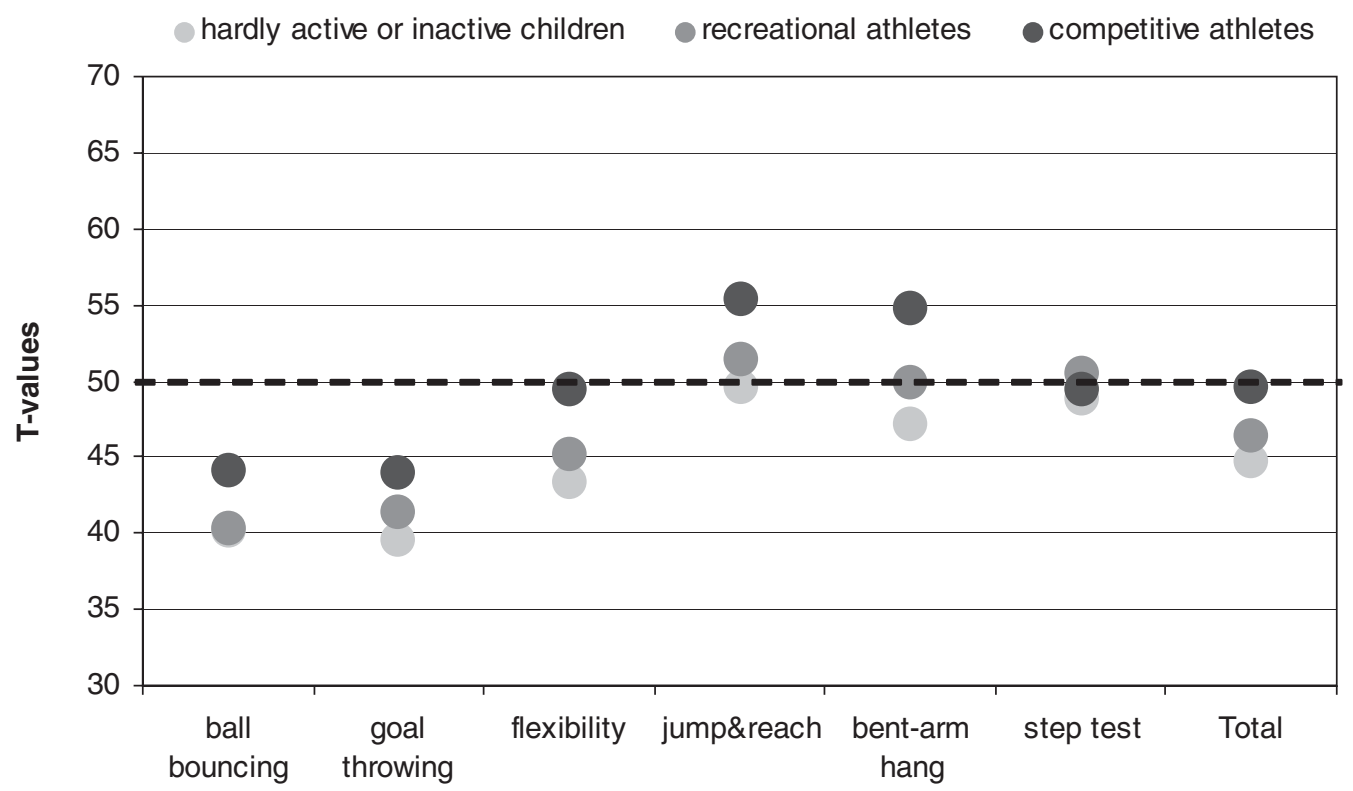

Figure 2. Motor fitness (mean) by self-assessment of sportiness $(\mathrm{N}=313)$.

club and the level of motor fitness. Members of sports club and children with a high PA in free time showed significant better test results than less actives. Further it is clear that children from families with a history of sports club affiliations and with no migratory background display a higher proximity to sports club. Sports-active parents thus assume an important role model for the exercise behavior of their children (Rommel et al., 2008; Sallis et al., 2000).

Otherwise and according to other studies (Brettschneider et al., 2006; Klaes et al., 2008; Rommel et al., 2008), the high importance of PA in life and school-seetings must be seen against the satisfactory fitness results and conspicuous motor disorders at the end of primary school. In the light of the findings, 


\section{SHS Web of Conferences}

the question obtrudes about the quality of today's exercise stimuli (variety, amount and intensity) in the context of free time and school sport activities. A critical evaluation would therefore be of considerable interest. There are many indications that the amount of time and the intensity of sporting activities of adolescents is increasingly in competition with, and is reduced by, other leisure time activities (Rommel et al., 2008). The multiplicity and differentiation of leisure time opportunities does not appear only to have led to a newly accentuated appreciation of sports, but rather to enhance even more the gap between the sports-active and non-sporting children and adolescents (Gerlach and Brettschneider, 2004).

As a result of the cross-sectional design of the present study as well as the lack of reference data from previous years, no normative trends can be established for Liechtenstein. Thus, as a follow-on study an analysis of the level of activity and the physical fitness of school children within the framework of a longitudinal study is desirable.

\section{Conclusions}

The capabilities in, and attitudes to, physical exercise which are acquired at school age form the basis for an active lifestyle later on as an adult (Tammelin, 2005; Hallal et al., 2006). The sooner that exercise is integrated into the daily routine, the sooner it becomes an automatic matter of course. The deficits in mobility and motor fitness must not be allowed to become habitual because of their long-term effects. They become increasingly difficult to correct with advancing age. Therefore guiding growing children towards an active lifestyle needs to attract the awareness of parents and the support of schoolcommunities as well. The example set by the parents plays a key role in promoting physical exercise. In addition school (in terms of school sports) carries a particular responsibility as facilitating authority. Over a relatively long period the school setting defines the daily routine for growing children and, at the same time, is the only institution (affiliated with an educational assignment) which brings all children into contact with exercise and sport.

However, sports clubs and associations, commercial suppliers, government authorities and political decision makers must not refuse their responsibility for providing conditions to promote physical exercise (e.g. creating safe routes to school) and in promoting the children's own understanding of their personal responsibility. Only based on realistic concepts and supported by a broad networking of all actors an incentive for a health-awareness lifestyle can be created and a positive change in behaviour can be initiated.

\section{References}

[1] Ahnert, J., Schneider, W. (2007) Development and stability of motor skills from preschool age to early adulthood. Findings of the Munich Longitudinal Study LOGIK. Zschr. Entwicklungspsych. Päd. Psych., 39, p. 12-24.

[2] Bös, K. (2003) Motorische Leistungsfähigkeit vom Kindern und Jugendlichen. In Schmidt, W. Hartmann-Tews, I., Brettschneider, W.-D. (eds.). Erster Deutscher Kinder- und Jugendsportbericht (p. 85-107). Schorndorf: Hofmann.

[3] Brettschneider, W.-D., Naul, R., Bünnemann, A., Hofmann, D. (2006) Übergewicht und Adipositas bei Kindern und Jugendlichen. Ernährungsverhalten, Medienkonsum und körperliche (In-)Aktivität im europäischen Vergleich. Spectrum Sportwiss., 18, p. 25-45.

[4] Gerlach, E., Brettschneider, W.D. (2004) Sportliches Engagement und Entwicklung im Kindesalter. Eine Längsschnittstudie. Spectrum Sportwiss., 16, p. 108-126.

[5] Graf, C., Dordel, S., Reinher, T. (eds.) (2006) Bewegungsmangel und Fehlernährung bei Kindern und Jugendlichen. Köln: Deutscher Ärzte Verlag.

[6] Hallal, P.C., Victora, C.G., Azevedo, M.R., Wells, J.C.K. (2006) Adolescent physical activity and health: a systematic review. Sports Med., 36, p. 1019-1030. 
Int. Conf. SOCIETY. HEALTH. WELFARE; Congr. of Rehabilitation Doctors of Latvia

[7] Hills, A.P., King, N.A., Armstrong, T.P. (2007) The contribution of physical activity and sedentary behaviours to the growth and development of children and adolescents: implications for overweight and obesity. Sports Med., 37, p. 533-545.

[8] Jackson-Leach, R., Lobstein, T. (2006) Estimated burden of paedriatric obesity and comorbidities in Europe. Part 1: The increase in the prevalence of child obesity in Europe is itself increasing. Int. J. Ped. Obes., 1, p. 26-32.

[9] Janz, K.F., Dawson, J.D., Mahoney, L.T. (2000) Tracking physical fitness and physical activity from childhood to adolescence: The Muscatine study. Med. Sci. Sports Exerc., 32, p. 1250-1257.

[10] Klaes, L., Rommel, A., Cosler, D. (2008) Entwicklung der Fitness von Kindern und Jugendlichen in Deutschland. In Klaes, L., Poddig, F., Wedekind, S., Zens, Y., Rommel, A. (eds.), Fit sein macht Schule. Erfolgreiche Bewegungskonzepte für Kinder und Jugendliche. (p. 29-43). Köln: Deutscher Ärzte Verlag.

[11] Kühnis, J. (2007) Stellenwert des Vereins- und Schulsports bei 11-20-Jährigen Jugendlichen in Liechtenstein. Schule heute, 1, p. 22-23.

[12] Kühnis, J. (2010) Health literacy - a superior educational objective. Eur. J. Phys. \& Health Educ., 3, p. 13-18.

[13] Kühnis, J., Walser, E. (2010) Trends in overweight and obese school children in Liechtenstein, 2004-2008. Eur. J. Phys. \& Health Educ., 4, p. 91-96.

[14] Must, A., Tybor D.J. (2005) Physical activity and sedentary behaviour: a review of longitudinal studies of weight and adiposity in youth. Int. J. Obes., 29, p. 84-96.

[15] Olds, T., Tomkinson, G., Leger, L., Cazorla, G. (2006) Worldwide variation in the performance of children and adolescents: an analysis of 109 studies of the 20-m shuttle run test in 37 countries. J. Sports Svi., 24, p. 1025-1038.

[16] Rommel, A., Lampert, T., Bös, K. (2008) Sport und Bewegung im Kindes- und Jugendalter ein Überblick über den aktuellen Forschungsstand. In Klaes, L., Poddig, F., Wedekind, S., Zens, Y., Rommel, A. (eds.), Fit sein macht Schule. Erfolgreiche Bewegungskonzepte für Kinder und Jugendliche (p. 3-27). Köln: Deutscher Ärzte Verlag.

[17] Sallis, J.F, Prochaska, J., Taylor, W. (2000) A review of correlates of physical activity of children and adolescents. Med. Sci. Sports Exerc., 32, p. 963-975.

[18] Steffen, B., Zahner, L., Puder, J., Kriemler, S. (2007) Das aktive Mitmachen im Sportverein von Kindern und ihren Eltern ist positiv assoziiert mit dem Fitnessgrad von Schulkindern. Schweiz. Zschr. Sportmed. Sporttraumatol., 55, p. 69-7.

[19] Strong, W.B., Malina, R.M., Blimkie, C.J.R., Daniels, S.R., Dishman, R.K., Gutin, B., Hergenroeder, A.C., Must, A., Nixon, P.A., Pivarnik, J.M., Rowland, T., Trost, S., Trudeau, F. (2005) Evidence based physical activity for school-age youth. J. Pediatr., 146, p. 732-737.

[20] Tammelin, T. (2005) A review of longitudinal studies on youth predictors of adulthood physical activity. Int. J. Adolesc. Med. Health, 17, p. 3-12.

Wang, Y., Lobstein, T. (2006) Worldwide trends in childhood overweight and obesity. Int. J. Ped. Obes., 1, p. 11-25.

[21] Zimmer, R. (2009) Handbuch der Bewegungserziehung. Grundlagen für Ausbildung und pädagogische Praxis. Freiburg: Herder. 